\title{
As categorias de tempo como contribuição para a distinção entre tipologias textuais
}

\author{
Simone SANT'ANNA ${ }^{1}$
}

\begin{abstract}
RESUMO: O presente artigo tem por objeto de estudo as projeções enunciativas de tempo como contribuição para a distinção entre descrição e narração com base na análise semiótica greimasiana. Foi apresentada uma análise qualitativa dos dados com base na sintaxe discursiva e nas categorias de tempo de Fiorin (2008). O corpus foi constituído por uma reportagem publicada no jornal Folha de São Paulo na data de 25 de novembro de 2008. A amostra foi composta pela manchete e por duas páginas do caderno Cotidiano, apresentando o tema das enchentes em Santa Catarina. A pesquisa foi motivada pelo fato de que possa haver uma diferença entre trechos que apresentam a descrição e a narração, observando-se as categorias de tempo. O objetivo principal desse estudo foi identificar, descrever e explicar como as categorias de tempo podem contribuir para uma análise das tipologias textuais. É importante esclarecer que não se trata de uma pesquisa sobre as definições e caracterizações das tipologias textuais. Mas, de um estudo sobre como as categorias temporais podem auxiliar na distinção entre essas tipologias.
\end{abstract}

PALAVRAS-CHAVE: semiótica; sintaxe discursiva; categorias de tempo.

\section{Introdução}

O presente artigo é uma colaboração para o processo de ensino-aprendizagem de leitura e produção textual, pois apresenta uma proposta de distinção entre tipologias textuais por meio de marcas lingüísticas. Vale ressaltar que o professor, para trabalhar com os alunos, deve se preparar teoricamente sobre os conteúdos a serem lecionados. Como contribuição será apresentado um exemplo de análise na qual os elementos que devem ser observados no texto para uma melhor compreensão das tipologias serão apontados. A análise fundamenta-se na semiótica de linha francesa e mostra, por exemplo, que o emprego de tempos verbais canônicos ou sua neutralização em seqüências tipológicas especificas podem produzir diferentes efeitos de sentido. $\mathrm{O}$ professor em sala de aula não deve empregar as terminologias apresentadas neste artigo e, sim, fazer com que os alunos observem os fenômenos aqui apontados. Entretanto, é necessário salientar a necessidade de evidenciar, para o aluno, tanto os objetivos quanto

\footnotetext{
${ }^{1}$ Mestranda em Língua Portuguesa pela UFRJ sob orientação da Prof. ${ }^{\mathrm{a}} \operatorname{Dr}^{\mathrm{a}}$ Maria Aparecida Lino Pauliukonis.
} 
as funções dos procedimentos de leitura, pois, muitas vezes, em sala de aula, o que chamamos de leitura não passa de mera decodificação. A análise, também, mostra que as marcas lingüísticas funcionam como base para a construção de sentido proporcionando a possibilidade de uma interpretação coerente e fundamentada por parte do aluno. Desse modo, essa análise contribui principalmente por evidenciar uma funcionalidade dos conhecimentos lingüísticos e textuais mediante a uma situação de comunicação real.

\section{A Teoria Semiótica de linha francesa}

A teoria semiótica de linha francesa foi fundada por A. J. Greimas. Tem por objeto de estudo descrever e explicar como se produz sentido no texto. Para isso, propõe uma análise imanente, ou seja, parte do texto e mostra que o contexto está presente no texto e não fora dele, esse aspecto é extremamente relevante, pois distingue a semiótica das outras teorias textuais; relacional, ou seja, um elemento só faz sentido em relação a outro (sintaxe) e estrutural do sentido, ou seja, só se pode chegar à enunciação pelas marcas deixadas no enunciado.

A semiótica apresenta o signo como resultado da forma do plano da expressão mais a forma do plano do conteúdo. Porém, a semiótica ultrapassa o estudo do signo como uma unidade de manifestação da linguagem, mostrando a possibilidade de analisar cada plano individualmente. Assim, a semiótica partiu da análise do plano do conteúdo e, posteriormente, focalizou seus estudos no plano da expressão.

Para a semiótica, a produção do sentido é construída através de um percurso gerativo que apresenta diferentes níveis de abstração: fundamental; narrativo; e discursivo. Todos esses níveis de abstração apresentam uma sintaxe e uma semântica.

O nível fundamental pode ser representado pelo quadrado semiótico abaixo:

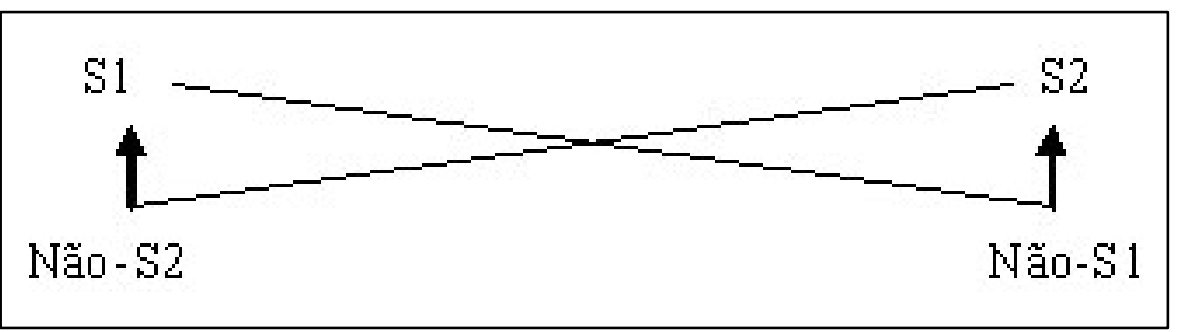

Caderno Seminal Digital Ano 16, nº 13, V. 13 (Jan.- Jun/2010) - ISSN 1806 -9142 
Esse nível é o primeiro momento de organização de sentido no texto. Como o sentido é relacional, só se apreende um elemento em contraste com outro elemento. Desse modo, S1 e S2 são contrários. S1 e não-S1 são contraditórios. E S1 e não-S2 são complementares. Assim, S1 é o sentido inicial que só pode ser apreendido em relação ao seu sentido oposto, representado por S2. O estágio não-S2 é intermediário entre S1 e S2, sendo complementar a S1 e contraditório em relação a S2. As categorias elementares podem ser positivas (eufóricas) ou negativas (disfóricas). Porém, o quadrado semiótico não dá conta das possíveis gradações entre esses elementos.

O nível narrativo é caracterizado pela entrada do sujeito em busca de um determinado valor. É importante ressaltar que o sujeito, nesse caso, não é sinônimo de pessoa, mas de algum elemento, seja pessoa ou não, que faz agir. A partir desse nível, as categorias do nível fundamental são convertidas em sujeitos e objetos de valor. Nesse nível, o enunciado é igual a um sujeito que está em conjunção ou disjunção com um objeto de valor.

\section{$\mathrm{PN}=\mathrm{F}[\mathrm{S} 1 \rightarrow(\mathrm{S} 2 \mathrm{n} \mathrm{Ov})]$}

A fórmula acima representa os programas narrativos (PN) que apresentam uma função (F) na qual um enunciado de fazer (S1) rege um enunciado de estado (S2) que está em conjunção $(\cap)$ ou disjunção $(\mathrm{U})$ com um objeto de valor $(\mathrm{Ov})$. Os programas narrativos constituem uma forma de organização dos enunciados que envolvem as ações dos sujeitos, os valores dos objetos e a relação entre eles.

O nível discursivo é a etapa na qual entra em cena o sujeito da enunciação responsável por transformar as estruturas narrativas em estruturas discursivas. São as marcas deixadas no enunciado pela enunciação. É nessa etapa que este artigo se desenvolve, pois é no nível discursivo que as projeções da enunciação no enunciado (actorialização, temporalização e espacialização) são estudadas. As projeções enunciativas pertencem ao estudo da sintaxe discursiva.

A debreagem é a operação pela qual a enunciação projeta as categorias de pessoa, tempo e espaço no enunciado. A debreagem é considerada enunciativa quando esta cria um efeito de aproximação da enunciação e é considerada enunciva quando cria um efeito de distanciamento. 
Os três níveis (fundamental, narrativo e discursivo) são articuláveis e responsáveis pela geração de sentido no texto.

\section{As categorias de tempo}

A projeção temporal é de extrema relevância na diferenciação dos trechos narrativos e descritivos, pois estes são caracterizados pelo caráter atemporal enquanto que aqueles são caracterizados pela seqüência cronológica de ações. Segundo Fiorin (2008), o tempo é uma categoria da linguagem, pois é intrínseco à narração.

É necessário salientar que o tempo lingüístico não é sinônimo de tempo cronológico. O tempo lingüístico pode ser caracterizado por ser o momento da enunciação o seu eixo ordenador e gerador e por estar relacionado à ordenação dos estados e transformações narradas no texto.

Nas categorias de tempo, o processo de embreagem e debreagem ocorrem de forma diferente das outras instâncias (pessoa e espaço).

Ao contrário da embreagem, que é a projeção, para fora da instância da enunciação, dos tempos que servem para constituir o enunciado, quer um enunciado que seja um simulacro da enunciação, quer um enunciado que não represente uma enunciação, a embreagem temporal é "o efeito de retorno à instância da enunciação, produzido pela suspensão da oposição entre certos termos" da categoria de tempo. (Greimas e Courtès apud Fiorin, 2008, p. 191)

A debreagem cria uma enunciação enunciada ou um enunciado enunciado.

Os dois sistemas temporais existentes na língua são o enunciativo, relacionado diretamente ao tempo da enunciação, e o enuncivo, ordenado em função de momentos de referência instalados no enunciado.

\section{Os te rqos enurciativos}

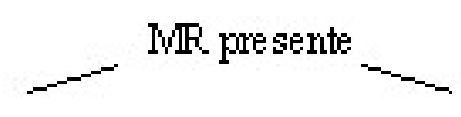

Concomitância

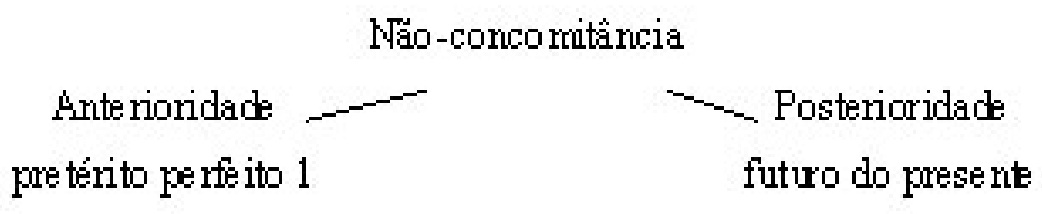


No presente pode ocorrer uma coincidência entre os três momentos estruturalmente relevantes na constituição do sistema temporal: MA (momento do acontecimento) $=$ MR (momento da referência) $=$ ME (momento da enunciação). Quando não ocorre essa coincidência, as relações ocorrem da seguinte maneira: $\mathrm{MR}=$ $\mathrm{ME}$ (presente pontual), MR $>\mathrm{ME}$ (presente durativo) e $\mathrm{MR}=\mathrm{MA}$ (presente omnitemporal ou gnômico). O pretérito perfeito 1 marca uma relação de anterioridade entre o momento do acontecimento e o momento de referência presente. E o futuro do presente indica uma posterioridade do momento do acontecimento em relação a um momento de referência presente.

Os tempos enuncivos, apresentam dois subsistemas: um centrado num momento de referência pretérito e outro, num momento de referência futuro:

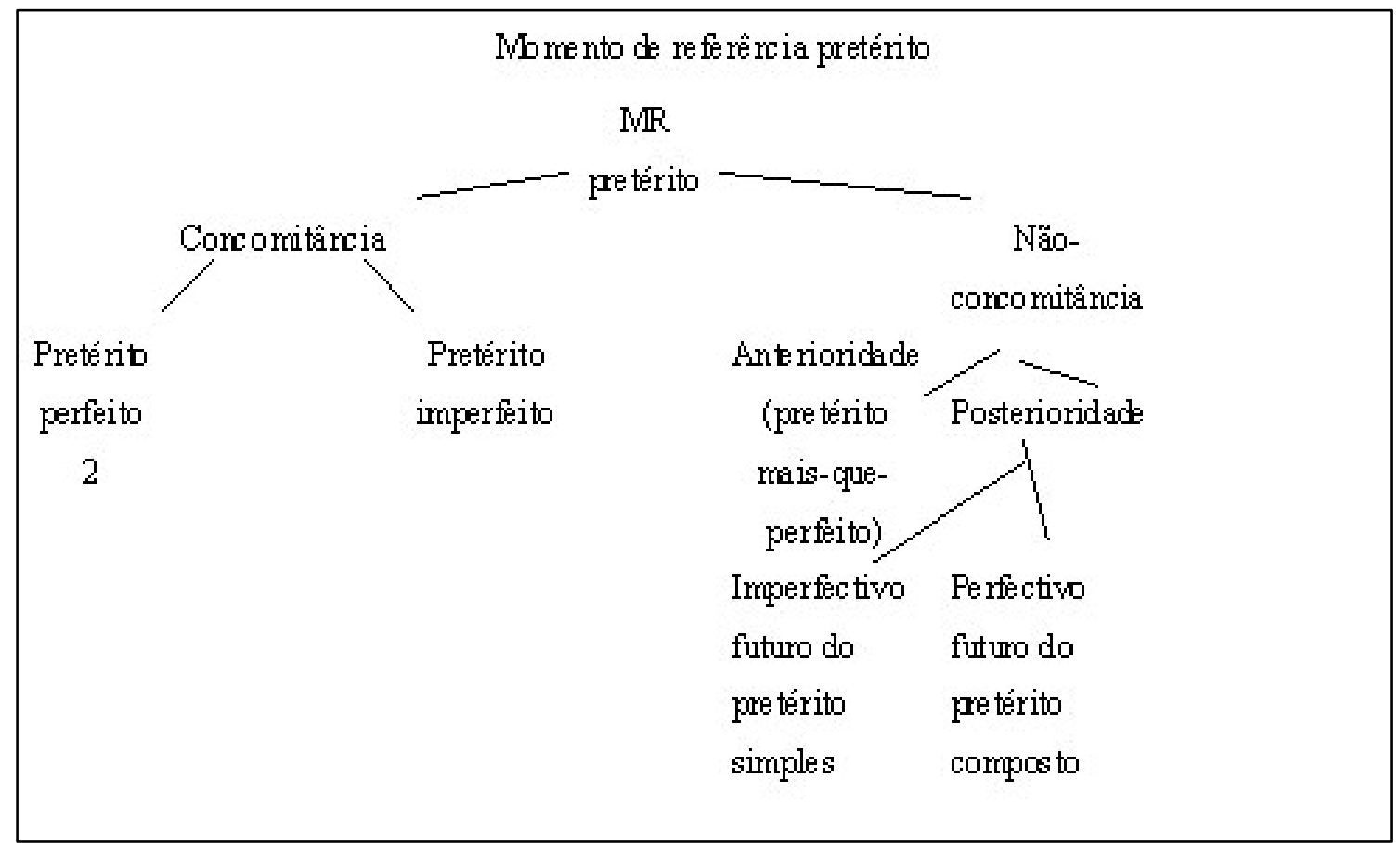

A concomitância do MA em relação a um MR pretérito pode exprimir-se tanto pelo pretérito perfeito 2 quanto pelo pretérito imperfeito. A diferença entre eles reside no fato de que cada um tem um valor aspectual distinto: o pretérito perfeito 2 assinala um aspecto limitado, acabado, pontual, dinâmico, enquanto o pretérito imperfeito marca um aspecto não-limitado, inacabado, durativo, estático. A nomenclatura pretérito perfeito 2 é utilizada para fazer uma diferenciação do pretérito perfeito 1 que pertence ao sistema enunciativo. Desse modo, o mesmo tempo verbal pode fazer parte ora do sistema enunciativo ora do sistema enuncivo o que acarreta uma certa dificuldade na análise dos sistemas temporais. 
A não-concomitância pode exprimir-se pelo pretérito mais-que-perfeito e pelo futuro do pretérito. O pretérito mais-que-perfeito indica uma relação de anterioridade entre o MA e o MR pretérito. E o futuro do pretérito exprime uma relação de posterioridade do MA em relação a um MR pretérito.

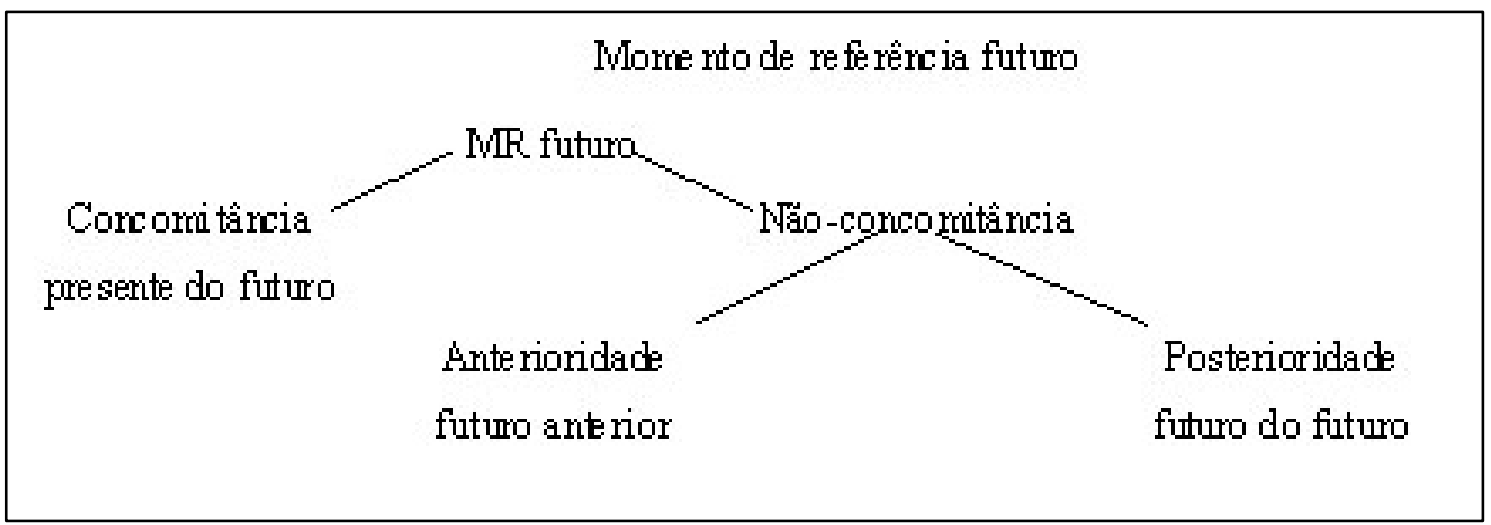

$\mathrm{Na}$ língua portuguesa, o presente do futuro não apresenta uma forma específica. É expresso por um futuro do presente simples ou um futuro do presente progressivo correlacionado a um futuro do presente do subjuntivo introduzido por uma conjunção. A anterioridade em relação ao MR futuro é indicada pelo futuro anterior, que, em nossa nomenclatura gramatical, é chamado futuro do presente composto. O MR pode ser manifestado por uma expressão de natureza adverbial ou por uma oração subordinada com um verbo no futuro do presente. A posterioridade em relação a um MR futuro é indicada pelo futuro do presente simples, que será, nesse caso, um futuro do futuro.

As categorias temporais não são projetadas no texto somente pelos tempos verbais, elas se realizam também por meio de advérbios, preposições e conjunções. Os advérbios de tempo articulam-se também em um sistema enunciativo (centra num MR presente $=\mathrm{ME}$ ) e um enuncivo (MR pretérito ou futuro inscrito no enunciado). Por outro lado, as preposições (ou locuções prepositivas) temporais organizam-se em torno da categoria topológica concomitância vs não-concomitância, e não apresentam um sistema enunciativo e um enuncivo como os advérbios. As conjunções temporais, por sua vez, não se distinguem num sistema enunciativo e num enuncivo, mas dividem-se em um sistema temporal e outro aspectual. 


\section{Análise da reportagem}

No que tange às categorias de tempo, optou-se por descrever os tempos verbais que poderiam exercer mais influência na distinção dos trechos narrativos e descritivos. Para analisar essas estruturas verbais foi necessário examinar todo o texto, para que fosse possível definir o que é narrado, ou seja, os eventos no tempo e o que é descrição do que é narrado. A descrição, embora apresente um caráter atemporal, não é sinônimo de ausência da estrutura verbal. Os trechos descritivos apresentam, na verdade, uma possibilidade de movimentação no eixo temporal. Quando esses trechos descritivos são utilizados a serviço de uma narrativa apresentam, geralmente, avaliações, explicações, detalhes e toda uma gama de informações que funcionam como apoio ao que está sendo narrado, tornando o texto dinâmico e próximo do leitor. Pode apresentar tempos verbais como o imperfeito, o presente atemporal, o infinitivo entre outros tempos, até mesmo o pretérito perfeito.

Geralmente, os trechos narrativos apresentam uma seqüência dos eventos que constituem a estória. Seus traços característicos são o predomínio do uso do pretérito perfeito e de verbos de ação. Cabe salientar que mesmo em textos narrativos pode-se observar a utilização de tempos verbais que são característicos da descrição como o imperfeito e o presente. Esse uso pode ser justificado pela intencionalidade do jornal em possibilitar uma dinamicidade na reportagem de forma a atrair a atenção do leitor. Carneiro (2005) afirma que os verbos que marcam a sucessão cronológica numa narrativa estão preferencialmente no pretérito perfeito do indicativo, podendo também aparecer no presente do indicativo (presente histórico). "Sobre o papel do imperfeito do indicativo: em alguns casos, ele só caracteriza uma descrição, mas em outros participa da narração, ora como ação a ser interrompida pelo pretérito perfeito, ora como ação contínua em que se intromete a ação do pretérito perfeito."

\subsection{Análise do exemplo 1}

(EX. 1):

Pelo menos 59 mortos, 43 mil pessoas obrigadas a abandonar suas casas, oito cidades ilhadas, famílias sem comida, água e luz. Os moradores de Santa Catarina não param de contabilizar os estragos provocados pela chuva na pior enchente desde 1974, 
quando 199 pessoas morreram. Em 1984, foram dois mortos e mais de 150 mil desabrigados.

Segundo a Defesa Civil do Estado, os deslizamentos de terra, que ocorrem desde a última sexta-feira principalmente no vale do Itajaí, provocaram a maioria das mortes.

Dos 43 mil desabrigados, 28.543 estão na casa de parentes e outras 14.511, em abrigos montados de emergência.

Os mortos são de Ilhota (15), Blumenau (13), Gaspar (10), Jaguará do Sul (6), Rodeio (4), Luiz Alves (4), Rancho Queimado (2), Benedito Novo (2), Brusque (1), Pomerode (1) e Bom Jardim da Serra (1).

Pelo menos 1,5 milhão de pessoas foram atingidas no Estado cerca de $25 \%$ da população. Em Blumenau, município com cerca de 20 mil desalojados, os moradores estão sem fornecimento de água potável e já existem sinais de desabastecimento de alimentos.

O problema é causado pela obstrução de rodovias que atendem ao município. No Estado, ao menos cinco rodovias federais estão com o tráfego interrompido. O mesmo ocorre com outras dez estaduais.

As chuvas no litoral norte, vale do Itajaí e Grande Florianópolis superaram no final de semana os recordes históricos, de acordo com o serviço meteorológico do Estado. A previsão é que elas persistam até amanhã." [Folha de São Paulo, caderno Cotidiano p. C1, em 25/11/08]

No primeiro exemplo, podemos observar, no primeiro parágrafo, um trecho descritivo que tem a função de listar e quantificar em parte os estragos provocados pela enchente. Em “não param de contabilizar" é possível perceber esse enunciado como um trecho narrativo dentro de um parágrafo descritivo. O verbo parar está no tempo presente que instaura um agora que é o momento da enunciação, ou seja, não param "agora" de contabilizar. Desse modo, esse trecho pertence ao sistema enunciativo.

A preposição, seguida do marco temporal ano de 1974, desde marca o início de outras enchentes ocorridas em Santa Catarina. A intenção é criar um efeito retrospectivo. O aspecto incoativo-durativo característico desta preposição pode ser observado da seguinte maneira: o ano de 1974 marca o início do processo de enchentes que marcaram o estado de Santa Catarina pelo poder de destruição que tiveram. Esse marco inicial é a incoatividade. No ano de 1984, ocorreu novamente uma grande enchente. A preposição em assinala um momento pontual inscrito no enunciado que mostra que, em algum outro momento passado, a enchente fez estragos. Essa recorrência mostra que de certo modo o processo de enchente possui uma duração. É importante destacar que a duração, nesse caso, não indica que a enchente teve início em 
1974 e está durando até os dias atuais, ou seja, até o momento de publicação da reportagem, mas que nesse intervalo de tempo tem ocorrido de forma pontual e repetida caracterizando o aspecto iterativo. A duração, portanto, refere-se à recorrência de grandes enchentes.

A conjunção quando apresenta aspecto pontual e indica simultaneidade entre o tempo que está sendo correlacionado a esta conjunção e o acontecimento, ou seja, indica que o quantitativo de pessoas mortas refere-se ao poder destruidor da enchente de 1974.

O verbo morrer apresenta concomitância em relação a um momento de referência pretérito que é o ano de 1974. A ação de morrer é acabada e descontínua em relação ao momento de referência. É também dinâmica e limitada ao período de referência pretérito. Esse é um exemplo de pretérito perfeito pertencente ao sistema enuncivo.

O verbo ir apresenta a mesma descrição do verbo morrer. A única modificação refere-se ao momento de referência que passa a ser o ano de 1984.

No segundo parágrafo, podemos observar um trecho narrativo. O verbo ocorrer pertence ao sistema enunciativo, pois além de estar no presente apresenta aspecto durativo e contínuo. É durativo porque ao momento de referência, que começa na última sexta-feira e marca o início das chuvas, é mais longo do que o momento da enunciação que é na terça-feira dia 25 de novembro de 2008, data da publicação da reportagem. O verbo provocar que está no pretérito perfeito, por sua vez, marca uma relação de anterioridade entre o momento do acontecimento, ou seja, das mortes e o momento de referência presente que é a data da publicação da reportagem.

No terceiro parágrafo, temos novamente uma descrição que tem a função de explicar a localização dos desabrigados. O verbo utilizado foi estar no presente com aspecto pontual.

O quarto parágrafo também é descritivo e tem a função de listar as cidades de origem e o quantitativo de mortos. O verbo utilizado foi ser também no tempo presente.

No quinto parágrafo, os trechos são predominantemente descritivos. $\mathrm{O}$ verbo ir no pretérito perfeito marca o momento em que as pessoas foram atingidas como anterior ao momento da enunciação (presente referente a data de 25/11/08). O verbo estar em "os moradores estão" instaura um agora que traz o texto de volta para o momento da enunciação. $\mathrm{O}$ mesmo ocorre com o verbo existir. Ambos são enunciativos. $\mathrm{O}$ advérbio já apresenta uma posterioridade pressuposta, pois a falta de alimentos não era esperada 
no momento presente e talvez somente em um momento posterior, mas esse é um fato que ocorreu antes do esperado e está acabado em relação ao momento da publicação da reportagem.

O sexto parágrafo deste exemplo é descritivo, pois apenas apresenta explicações e detalhes sobre as rodovias. Os verbos ser, estar e ocorrer estão todos no presente e fazem parte do sistema enunciativo.

No sétimo e último parágrafo deste primeiro exemplo, os períodos são descritivos, mas a sua estrutura poderia ser considerada narrativa se apresentasse uma seqüência de ações. $\mathrm{O}$ verbo superar está no pretérito perfeito e pertence ao sistema enunciativo. O trecho "no último final de semana" reforça a anterioridade do fato em relação ao dia da publicação da reportagem, uma terça-feira dia 25 de novembro de 2008. Em “a previsão é que elas persistam” podemos observar que o verbo persistir está no presente do subjuntivo e apresenta um efeito de posterioridade que é reforçado tanto pela preposição até quanto pelo advérbio amanhã. $O$ verbo ser da oração principal está no presente e traz o texto de volta ao momento da enunciação. A preposição até apresenta o aspecto terminativo-durativo, ou seja, as chuvas apresentam um final (terminativo) no momento posterior que será amanhã e, que, nesse caso, ainda não aconteceu. Porém, enquanto esse momento posterior não chega, elas continuaram ocorrendo (durativo). O advérbio amanhã reforça ainda mais a posterioridade em relação ao presente enunciativo.

\subsection{Análise do exemplo 2}

(EX. 2):

Já do avião, chegando à cidade de navegantes, a $114 \mathrm{Km}$ de Florianópolis, é possível constatar: o Estado virou um mar de lama. Não há como trafegar pelas estradas. Quase não há fluxo rumo a Blumenau, epicentro das enchentes. Rodovias que cortam a região se tornaram afluentes de um grande rio. $\mathrm{O}$ cenário é de destruição.

No aeroporto de Navegantes, nenhum taxista se arrisca a tentar viagem para outras cidades da região. A recomendação é dos policiais rodoviários federais e estaduais.

O trânsito na cidade dá indícios do caos. Semáforos não funcionam e o som das sirenes dos carros de bombeiros é constante.

Grande parte do comércio está de portas fechadas. Nas escolas, as aulas foram suspensas e não há fornecimento de água.

Caderno Seminal Digital Ano 16, nº 13, V. 13 (Jan.- Jun/2010) - ISSN 1806 -9142 
A reportagem tentou percorrer a BR-470, em direção a Blumenau, mas um trecho alagado pelo rio Itajaí-Açu interrompeu a curta viagem após cinco quilômetros.

No meio da pista, havia um barco, usado para resgatar moradores, parado. Dos dois lados da estrada, o cenário de casas debaixo d'águas impressiona.

A Defesa Civil do município diz que 4.000 pessoas, dentre os 52 mil habitantes da cidade, tiveram que deixar suas casas. Em um abrigo improvisado em um colégio, 242 pessoas estão alojadas. Entre elas um bebê, de um mês, que foi retirado de casa pela mãe, com água na cintura anteontem.

"Só tive tempo de pegá-la nos braços, segurar um pacote de fraldas e uma lata de leite em pó e deixar a casa", disse a mãe da criança, Débora Vaz, 29. A casa dela está com água até o teto. "Perdi o pouco que tinha." [Folha de São Paulo, caderno Cotidiano p. C3, em 25/11/08]

No segundo exemplo, logo no primeiro parágrafo, podemos observar o advérbio já que pode ser interpretado de duas formas distintas. Na primeira, esse advérbio não apresenta valor temporal e sim espacial correspondendo a algo como lá do avião ou simplesmente do avião. Sua utilização, todavia, cria um efeito de surpresa diante do cenário construído pela enchente. Nessa segunda interpretação, o advérbio já é temporal e seu traço de posterioridade é reconhecido pelo fato de que não houve necessidade de estar em terra firme para contemplar os estragos na cidade, ou seja, seria pressuposição estar no local primeiro para que o cenário pudesse ser visualizado e descrito. $\mathrm{O}$ traço concomitância aparece com o momento de chegada, que é o momento da visualização do local. E o traço acabado também, pois o fato já aconteceu em relação ao momento presente marcado pela data de publicação da reportagem. Os verbos chegar, e ser, no gerúndio e expressando um presente, mostram uma embreagem enunciativa que ocorre pela neutralização entre concomitância e anterioridade, ou seja, do presente pelo pretérito perfeito. Essa embreagem cria um efeito que faz com que o passado se presentifique, ou seja, cria a ilusão de que o fato está ocorrendo naquele exato momento e o enunciatário participa da cena através do que está sendo visto e descrito pelo enunciador. Sabe-se que o fato ocorreu antes do momento da enunciação (25 de novembro de 2008), entretanto não há uma data exata que comprove o momento a chegada do jornalista. Essa anterioridade, porém, não foi expressa pelo pretérito perfeito e sim pelo presente. O verbo virar no pretérito perfeito mostra que de fato o evento já aconteceu. É a prova da anterioridade. 
O verbo haver foi utilizado nesse trecho descritivo no presente para criar um efeito de corte no tempo que evidencia o cenário de destruição. O verbo cortar é um exemplo de presente omnitemporal, pois o fato das rodovias cortarem a região pode ser identificado como um estado imutável. O verbo tornar também faz parte do sistema enunciativo e é marcado pela anterioridade e pelo traço de ação acabada expressa pelo pretérito perfeito. $\mathrm{O}$ verbo ser no presente cria um efeito de retorno ao momento da enunciação. Além disso, acrescenta um valor de verdade que se estende desde o momento da visualização do cenário pelo jornalista ao momento da enunciação que é marcada pela publicação da reportagem e se presentifica a qualquer instante em que a reportagem for lida.

No segundo parágrafo, os verbos arriscar e ser, ambos no presente, apresentam o mesmo tipo de debreagem descrita no parágrafo anterior. O mesmo efeito também ocorre com os verbos dar, funcionar e ser no terceiro parágrafo.

No quarto parágrafo, o verbo ir, no pretérito perfeito, mostra uma anterioridade do fato em relação ao que está sendo descrito até então. Os verbos estar e haver acrescentam um traço de duração.

O quinto parágrafo apresenta um trecho narrativo expressos pelos verbos tentar e interromper no pretérito perfeito. $\mathrm{O}$ teor narrativo está presente na sucessão desses dois acontecimentos. Quanto ao advérbio após é provável que apresente um caráter híbrido entre o valor espacial e o valor temporal funcionando como um advérbio de seqüencialização inserido no interior desse pequeno trecho narrativo.

No sexto parágrafo o verbo impressionar no presente traz de volta à cena enunciativa criando efeito de realidade sendo descrita no momento em que realmente ocorre.

No sétimo parágrafo, o verbo dizer caracteriza uma debreagem do tempo presente pelo pretérito perfeito. $\mathrm{O}$ verbo ter no pretérito perfeito marca a anterioridade em relação ao momento em que a Defesa Civil se pronunciou. O verbo estar faz um retorno ao momento da enunciação com aspecto durativo. $\mathrm{O}$ verbo ir retorna a um momento anterior à enunciação que é marcado pelo advérbio anteontem.

No oitavo, a utilização do discurso direto caracteriza uma debreagem de segundo grau na qual o narrador delega voz a uma outra pessoa que é instaurada como interlocutor. Os verbos ter e perder, ambos no pretérito perfeito, apresentam traços de uma anterioridade do fato de abandonar a casa em relação ao momento da enunciação 
dessa outra pessoa representada pelo nome Débora. O verbo dizer no pretérito perfeito mostra que o momento da declaração da Débora foi anterior ao momento da enunciação, ou seja, os momentos de enunciação da Débora e do narrador são distintos. O momento enunciativo da Débora ocorre quando ela dá seu depoimento para o jornalista e o momento enunciativo do narrador ocorre concomitante ao da publicação da reportagem. O verbo estar, no presente durativo, mostra que a casa foi e continua alagada fazendo um retorno ao momento da enunciação.

\section{Conclusão}

Algumas sugestões para a aplicação desse tipo de análise em sala de aula: em primeiro lugar, nunca subestime seus alunos; escolha os textos a serem trabalhados de acordo com os níveis de linguagem e de interesse por parte dos alunos; apresente as atividades de observação textual (se possível acione o conhecimento de mundo dos alunos) e de análise textual (momento de interação entre a análise do professor e as análises dos alunos) para que o aluno perceba a funcionalidade do texto e os efeitos de sentido criados por meio das marcas linguísticas; é importante esclarecer para os alunos quais serão os objetivos de leitura e mostrar o caminho para que eles possam alcançar esses objetivos; simplificar a complexidade da tarefa, ou seja, evidenciar o fenômeno e não utilizar nomenclaturas desnecessárias ao nível de conhecimento deles; promover a interação entre os alunos de modo a facilitar o processo de análise; e sugerir tarefas de produção textual ou de escolha textual que possibilitem a elaboração de uma seqüência didática de forma colaborativa entre o professor e os alunos.

Este artigo estudou as projeções enunciativas de tempo como contribuição para a distinção entre descrição e narração com base na análise qualitativa das categorias de tempo de Fiorin (2008) que é uma das categorias da sintaxe discursiva do nível discursivo da semiótica greimasiana. O corpus foi constituído por uma reportagem publicada no jornal Folha de São Paulo na data de 25 de novembro de 2008 sobre a tragédia da enchente ocorrida em Santa Catarina. A amostra composta por dois trechos destacados dessa reportagem mostrou que havia mais trechos descritivos do que narrativos. $\mathrm{Na}$ análise dos tempos verbais, em geral, ocorreu um predomínio de tempos verbais no passado nos trechos narrativos e um predomínio de tempos verbais no presente nos trechos descritivos como já era esperado. Entretanto, muitas vezes, o tempo presente apareceu como uma neutralização entre o presente e o pretérito perfeito.

Caderno Seminal Digital Ano 16, nº 13, V. 13 (Jan.- Jun/2010) - ISSN 1806 -9142 
Conseqüentemente, presente e pretérito perfeito foram tempos verbais comuns às duas tipologias em questão.

A contribuição das categorias de tempo segundo a semiótica, na verdade, está em partir da estrutura lingüística para buscar os efeitos de sentido que esta causa na dinâmica textual. De fato, deve haver uma distinção entre os modos de organização ou tipologias textuais narrativas e descritivas, entretanto para evidenciar qualquer afirmação a respeito seria necessário realizar uma pesquisa com essas tipologias em um número maior de reportagens com o cuidado de comparar jornais destinados a públicos distintos. Além de acrescentar outros gêneros textuais de modo a confirmar as características de cada tipologia que se mantêm constantes independentemente do gênero analisado.

\section{Referências bibliográficas}

BARROS, D. L. Estudos do discurso. In: J. L. FIORIN, Introdução à lingüística II: princípios de análise (pp.187-219). São Paulo: Contexto, 2003.

BENVENISTE, É. Da subjetividade na linguagem. In: , Problemas de lingüística geral I (pp.284-293). Campinas, SP: Pontes, 1995.

O aparelho formal da enunciação. In: , Problemas de lingüística geral II (pp.81-90). Campinas, SP: Pontes, 1989.

CARNEIRO, A. D. Pré-Vestibular: oficina do texto. Rio de Janeiro: CECIERJ, 2005.

FIORIN, J. L. As astúcias da enunciação: as categorias de pessoa, espaço e tempo. São Paulo: Ática, 2008. 